\title{
Prácticas culturales en red: reflexión sobre la participación y producción de los internautas
}

\author{
Networked cultural practices: \\ reflection on the participation and \\ production of Internet users
}

\author{
Gonzalo Andrés (Argentina) \\ Universidad Nacional de Entre Ríos \\ gonzaloandres4@gmail.com
}

\section{Resumen}

Este trabajo reflexiona sobre los modos en que son teorizadas la participación y la producción de materiales en Internet. Mientras que algunos autores plantean que con la red se han fortalecido prácticas colaborativas que permiten la creación, edición, distribución y acceso de una infinidad de bienes culturales, otros, en cambio, discuten estas afirmaciones, al considerar que en la red todo acontece como si el internauta fuese activo, ya que en general lo que existe es una transmisión de contenidos digitales.

Palabras clave: participación, producción, colaboración, internautas.

\section{Abstract}

This paper reflects on the ways in which participation and production of online materials are theorized. While some authors argue that the network has strengthened collaborative practices that enable the creation, editing, distribution and access to a myriad of cultural goods, others, however, discuss these claims, believing that everything happens on the network as if the internet user was active, since what actually happens is a transmission of digital contents.

Keywords: participation, production, collaboration, internet users.
FECHA DE RECEPCIÓN:

FECHA DE REVISIÓN:

APROBACIÓN:
8 de marzo de 2012

20 de abril de 2012

30 de abril de 2012
Para citar este artículo / to cite this article Andrés, G. (2012). Prácticas culturales en red: reflexión sobre la participación y producción de los internautas. Poliantea 8 (14), 97-1 10. 


\title{
Prácticas culturales en red: reflexión sobre la participación y producción de los internautas
}

\author{
Gonzalo Andrés \\ Licenciado en Comunicación Social por la Universidad Nacional de Entre Ríos. Cursa el \\ Doctorado en Comunicación Social, en la Universidad Nacional de Rosario (Argentina). Becario \\ del Consejo Nacional de Investigaciones Científicas y Técnicas (Conicet), Argentina.
}

\section{Introducción}

Las sociedades contemporáneas están viviendo un proceso de digitalización creciente de la praxis vital. Las innovaciones en informática, electrónica y telemática modifican las estructuras sociales y los contextos culturales. El uso expandido de computadoras y teléfonos móviles con conexión a Internet ya forma parte de la vida cotidiana; transforman, no solo las formas de comunicación, sino también las instancias de socialización, el funcionamiento de la economía, las prácticas pedagógicas y los consumos culturales.

La tecnología digital permitió la creación y difusión de conocimientos, reestructuró las relaciones interpersonales y las prácticas de consumo, posibilitó el acceso a más bienes culturales, cambió el modo de informarse y la relación entre los medios y su público. Es un fenómeno que tiene un impacto profundo en todas las prácticas humanas y que redefine el mapa cultural contemporáneo. Su aparición es un hecho comparable únicamente con la invención de la rueda, el reloj o la imprenta, artefactos que han modificado el curso de la historia de la humanidad.

Debido al desarrollo de una serie de herramientas (que pueden denominarse interactivas), como el correo electrónico, los foros de discusión, las conversaciones electrónicas, los diarios cibernéticos y las redes sociales, los 
usuarios pueden mantener una comunicación virtual fluida. También aparecieron redes sociales mediatizadas - con las cuales se pueden mantener relaciones interpersonales en línea-que han tenido una gran expansión recientemente. De esta forma, hoy se puede interactuar a través de la red con personas desconocidas en el mundo real: muchos usuarios se reúnen para dialogar o trabajar con otros, ubicados en diferentes lugares del planeta. Puede afirmarse, entonces, que las posibilidades de interrelación con otras personas se expanden enormemente debido a este proceso de digitalización y eso constituye una reestructuración de las relaciones sociales, laborales y personales.

Al mismo tiempo, los programas y sitios de descarga de contenidos o de consumo en línea permiten acceder y distribuir los contenidos digitales. Es decir que la red posee cierta funcionalidad que da lugar a espacios de relación e intercambio, no solo entre los internautas, sino también entre estos y los bienes simbólicos.

La red se caracteriza por facilitar el intercambio de mensajes, textos, audios, videos y aplicaciones creados por los usuarios. Esto se evidencia, por ejemplo, en las páginas webs de descarga directa de películas, música o libros; en la lectura extensiva y fragmentaria de los hipertextos y su escritura conjunta o colaborativa; en las prácticas de compartir y transmitir contenidos en las redes sociales mediatizadas; en los sitios para editar o cargar videos en línea; o en las redes de intercambio de información.

Así pues, más allá de que tener acceso a los bienes no signifique necesariamente que sean consumidos (por ejemplo, es posible descargar una película y no verla), puede decirse que las tecnologías digitales modifican los modos de producción, distribución, acceso, recepción y uso de los bienes culturales, y les otorga, a su vez, protagonismo a los usuarios que en ellas participan, debido a que pueden $s u$ bir - a la red- los bienes que ellos han hecho. Asimismo, son frecuentes la combinación y la yuxtaposición, el cut and paste (cortar y pegar) y el manejo de las imágenes, los sonidos y los textos mediante la utilización de aplicaciones informáticas de edición de audio y video, todas, prácticas en las que los usuarios se apropian de los materiales y los modifican.

Por lo tanto, la producción cultural actual no puede pensarse solamente desde el punto de vista de las estrategias de mercado de las industrias del entretenimiento, sino que 
también es necesario tener en cuenta las prácticas de edición/reinvención/transmisión de materiales que llevan a cabo los internautas. Las tecnologías digitales han generado nuevas opciones que redefinen los límites y reconfiguran la interactividad entre las personas y, a su vez, entre estas y los materiales.

El objetivo de este trabajo - de corte ensayístico- es justamente el de analizar las condiciones y posibilidades de participación y la producción cultural en Internet, a partir de algunos abordajes teóricos, que en principio parecen ser contrapuestos pero que también pueden vincularse. Primero se hará referencia a algunos autores que encuentran en este fenómeno posibilidades concretas de cambios en los modos de concebir la producción cultural gracias a la actividad de los usuarios. Luego se mencionará a algunos ensayistas que critican estas nociones y enmarcan la actividad de los internautas dentro de la lógica global del modo de producción capitalista.

\section{Hacia una cultura digital participativa}

El uso masivo de tecnologías digitales fortaleció la aparición de prácticas culturales apoyadas en la conectividad, la interactividad y la ubicuidad. Las plataformas de la red basadas en un intercambio horizontal entre pares permiten la existencia de espacios de producción, apropiación y uso de contenidos de carácter, gratuito, más allá de los derechos de autor o la propiedad intelectual individual. Estos ámbitos generados para y por el procomún, se basan en que los internautas pueden tener a su alcance diversos contenidos, para apropiarlos, mezclarlos, editarlos y difundirlos nuevamente. Pero además, junto con el acto interactivo de intercambiar datos, se generan procesos creativos de construcción colectiva (Lévy, 2004). En estos sitios, una parte importante de los contenidos es subido a $-\mathrm{y}$ retransmitido en - la red por los internautas. $\mathrm{O}$ sea que una parte considerable de la información que circula por la red es generada y consumida por las personas que navegan por ella.

Para referirse a estas prácticas algunos autores han introducido términos novedosos con la finalidad de 
explicar los modos de producción y de intercambio particulares de las tecnologías digitales, que se caracterizan por permitirles a los usuarios generar contenidos y difundirlos. Así, puede nombrarse a los argentinos García Canclini (2007), Piscitelli (2009) o Urresti (2008), quienes utilizan el vocablo prosumidor (que fusiona las palabras "productor" y "consumidor"), inventado por Alvin Toffler en 1980, en su libro La tercera ola.

Un prosumer no tiene fines lucrativos, solo participa en un mundo digital de intercambio de información, tal es el caso del P2P, redes pares intercambiables. [...] son cada vez más las personas involucradas que suben información a la red, y a su vez son consumidores de la misma, creando así un abanico de información en todos los sentidos (Piscitelli, 2009, p. 255).

Aparecen, pues, espacios de construcción colectiva, colaborativa, asociativa, en los que los internautas se interrelación e intercambian todo tipo de contenidos. De esta forma estaría emergiendo un tipo de consumidor que interviene los materiales existentes y que a la vez produce nuevos contenidos digitales y los comparte virtualmente, justo por las características singulares de estas tecnologías.
Esta situación motivó a algunos autores a pregonar la emergencia de una cultura participativa (Jenkins) o de una inteligencia colectiva (Lévy). Según Lévy (2004), con la red apareció un movimiento de interconexión generalizado que acelera la integración entre los internautas y que construye una inteligencia colectiva, cuya característica es la de que el saber está repartido en todas partes ("todo el mundo sabe algo") y, por lo tanto, todo el conocimiento está en la humanidad: "No existe ningún reservorio de conocimiento trascendente y el conocimiento no es otro que lo que sabe la gente" (Lévy, 2004, p. 19). Es por eso que compartir información en la red es un modo de construir conocimiento colaborativo.

Este autor tunecino considera que la inteligencia colectiva solo comienza con la cultura y aumenta con ella, ya que pensamos con ideas, lenguajes y tecnologías producidas en sociedad. De esta forma, la estructura reticular de los medios digitales interactivos facilitará un pensamiento colaborativo, que se inventa y pone en movimiento constantemente:

$\mathrm{Al}$ interactuar con diversas comunidades, los individuos que animan el espacio del conocimiento, lejos de ser los miembros intercambiables 
de castas inmutables, son a la vez singulares, múltiples, nómadas y en vías de metamorfosis (o de aprendizaje, es lo mismo) permanente (Lévy, 2004, p. 21).

En este contexto se entiende por qué la aparición de una inteligencia colectiva de la red significa para Lévy la reaparición de formas de saber que estaban relegads a un segundo plano: emerge una creciente y acelerada conexión interpersonal que constituye una nueva forma de relación que no se deja totalizar, ya que integra a todos mediante una interacción generalizada.

En esta dirección, el académico y consultor empresarial Henry Jenkins afirma que con Internet estaría apareciendo un nuevo prototipo de cultura basado en la participación masiva de internautas. Debido a esta producción social de contenido, se estarían consolidando grupos de expresión autónomos en la web y en las redes sociales. En este sentido, la digitalización se vería acompañada por una cultura participativa en línea, en cuyo ámbito habría un flujo de ideas libre y democrático:

La cultura participativa está emergiendo como la cultura que absorbe y responde a la explosión de las nuevas tecnologías de los medios de comunicación que hacen posible que el consumidor promedio archive, anote, se apropie y recircule el contenido de medios en nuevas y potentes formas. Un enfoque en la expansión del acceso a las nuevas tecnologías nos lleva lejos si también se fomentan las habilidades y conocimientos culturales necesarios para implementar esas herramientas a nuestros propios fines' (Jenkins, 2006, p. 8, traducción propia).

Esta cultura participativa característica de la red podría influenciar en el funcionamiento de las instituciones políticas y económicas tradicionales producto de un nuevo tipo de intervención por parte de las personas. Lo que, dicho en otras palabras, significa que la cibercultura instaura un principio social basado en que el público influye en el contenido de los medios y, de ese modo, estructura y controla la comunicación (v. Rüdiger, 2011). Es decir que las tecnologías digitales habrían diseminado el conocimiento de manera horizontal, otorgándole mayor poder al individuo.

1 "Participatory culture is emerging as the culture absorbs and responds to the explosion of new media technologies that make it possible for average consumers to archive, annotate, appropriate, and recirculate media content in powerful new ways. A focus on expanding access to new technologies carries us only so far if we do not also foster the skills and cultural knowledge necessary to deploy those tools toward our own ends". 
Por lo tanto, puede afirmarse que Internet ofrece varias y variadas posibilidades que facilitan la cooperación y la interactividad entre los usuarios. Esto no significa, por supuesto, que compartir contenido sea algo novedoso, pero sí puede decirse que la interfaz digital puede potenciar o dinamizar estas prácticas: en la actualidad más internautas comparten contenido con otros, de más cantidad de fuentes, más regularmente y mucho más rápido.

En suma, de acuerdo con Jenkins, en la red aparecen espacios en los cuales se impulsa - voluntaria o involuntariamente, implícita o explícitamente- la construcción colaborativa y activa de nuevas relaciones sociales basadas justamente en nuevos dispositivos. Entonces sería correcto analizar a Internet como un ámbito de cooperación y lucha, un terreno abierto a las contestaciones $\mathrm{y}$ a las disputas que se manifiesta en discusiones por nuevas legislaciones, en empresas monopólicas que intentan regular las acciones de los internautas y aprovechar la red para objetivos mercantiles.

Hay internautas que fomentan un uso abierto, gratuito e igualitario de la tecnología para impulsar modos altruistas de elaborar y compartir información. Por ello Jenkins proclama la aparición de una cultura participativa, donde la colaboración y la conectividad serían sus puntos nodales. De conformidad con este autor, la sociedad se encuentra en plena revolución cultural, basada en la expansión de dispositivos digitales, que tiende a reducir el poder de las grandes empresas multimediáticas a favor de los públicos.

Estas afirmaciones se sostienen en la aparición de actores sociales léase, los internautas- que no forman parte de este conglomerado de empresas del entretenimiento pero que utilizan las formas creativas y participativas de la sociedad actual para producir bienes culturales. En el sentido, Manuel Castells sostiene:

El sistema mediático se caracteriza por la concentración global de empresas, la diversificación de la audiencia (incluyendo la diversificación cultural), la versatilidad tecnológica y multiplicidad de canales, y la autonomía creciente de una audiencia equipada con Internet, que ha aprendido las reglas del juego, a saber: todo lo que constituye una experiencia mental colectiva es virtual, pero esa virtualidad es una dimensión fundamental de la realidad de todo el mundo (Castells, 2004, p. 56). 
Ahora bien, a esta altura es necesario hacer algunas salvedades. En primer lugar, no todos los internautas producen contenidos, sino que son usuarios "estándar" que únicamente navegan por algunos sitios específicos y envían correos electrónicos. Además, está claro que pueden encontrarse algunos ejemplos de estas prácticas en espacios y ámbitos anteriores a la aparición de dichas tecnologías, sin embargo sí resultan novedosas la masividad y la mediación técnica, que son sus condiciones de posibilidad.

En segundo lugar, no es posible que esta forma emergente de producción, distribución y consumo reemplace a otras formas existentes, sino que es probable que las complemente. Además está claro que no toda la producción de bienes culturales se realiza en la red. Es más, el mundo en línea no podría existir si perdiese las referencias con la realidad fuera de línea. Es por eso que este modelo de producción y consumo par-par no reemplazará de ninguna manera los modelos productivos establecidos en los mercados tradicionales de bienes y servicios para satisfacer necesidades básicas, como la alimentación o el transporte, ni mucho menos las operaciones financieras del capital concentrado. De hecho, la economía del ciberespacio agrupa a las empresas en grandes redes de relaciones de interdependencia en cuyo seno comparten actividades e intereses (Rifkin, 2000).

En tercer lugar, esta posibilidad de realizar copias y distribuir todo lo digitalizado (Bunz, 2007) entra en conflicto, no solo con las lógicas de apropiación de conocimiento, sino también con los regímenes de propiedad y de autoría. Esta situación se evidencia en la Ley Sinde de Economía Sostenible, de España, sancionada en el 2011, en la clausura del sitio de descargas Megaupload por parte del FBI o en los proyectos de la Cámara de Representantes de Estados Unidos como Stop Online Piracy Act (SOPA) (acta de cese a la piratería en línea) y Protect IP Act (PIPA) (Ley de Protección de IP). Pero no nos referiremos a este tema en particular, ya que la dimensión jurídica de ese problema supera los objetivos de este artículo.

Recapitulemos: en la actualidad existe un discurso sobre las potencialidades de las tecnologías digitales que tiene a la conexión-participaciónproducción como sus ejes centrales. Como se planteó, algunos autores que sostienen esta postura son Henry Jenkins, Pierre Lévy, Alejandro Piscitelli 
y Manuel Castells. No obstante, estos argumentos son discutidos por otros autores, un tanto más críticos de este proceso de digitalización de la praxis vital (aunque no se opongan totalmente a él). Algunos de ellos son, por ejemplo, Dominique Wolton, Greg Goldberg y Slavoj Žižek. A continuación se presentarán brevemente algunos de sus planteamientos.

\section{La sensación de estar activo}

Wolton sostiene que otorgarle potencialmente la opción de intervención al usuario es una característica que diferencia a Internet de los medios anteriores. Este investigador francés afirma que, efectivamente, una persona se siente activa cuando está frente a una computadora:

La interacción asegurada por el teclado produce una sensación de responsabilidad y de acción [...] Con la computadora, el usuario tiene la sensación de ser el actor de lo que hace. Es la fuerza del do it yourself (Wolton, 2007, pp. 254-255).

En contraposición a la televisión, no recibe las imágenes, sino que tendría la sensación intensa de elegir, pero justamente no sería más que eso.

Asimismo, la mediación técnica del teclado o del celular es pensada por Žižek en su obra El acoso de las fantasías. Allí contrapone a la noción de interactividad el término "interpasividad", traducido como actividad pasiva realizada por medio de otro. En este sentido, los usuarios se sentirían activos, pero en realidad solo actuarían mediante un "otro", en este caso una máquina (el autor pone como ejemplo una videocasetera utilizada por el televidente para grabar una película mientras realiza otra actividad):

En el caso de la interpasividad, yo soy pasivo por medio del otro, es decir, le cedo al otro el papel pasivo (del goce), mientras yo puedo permanecer involucrado [...] Esto nos permite proponer la noción de falsa actividad: crees que estás activo, mientras que tu verdadera posición, como está encarnada en el fetiche, es pasiva (Žižek, 2007, p. 139).

Así pues, la actividad del internauta sería una falsa actividad, ya que en realidad es un aparato el que realiza la actividad de mirar, navegar e, incluso, gozar. Desde esta perspectiva, la computadora o el teléfono móvil son los que actúan y, por lo tanto, la participación no sería tal: todo acontece como si el usuario fuese activo al intervenir en las redes y producir contenidos, pero en la mayoría de los casos solamente se encuentra delante de un 
aparato seleccionando opciones y navegando de un sitio a otro.

Es decir, desde esta perspectiva la red puede pensarse como un conjunto de interfaces prediseñadas que ponen a disposición de los internautas un conjunto de materiales y les permiten elegir determinadas opciones para su uso. A partir de este rasgo constitutivo de la red, Žižek (2007) sospecha que la máquina actuaría como un "amo", cuya principal función es decirle al sujeto qué es lo que desea y qué debe hacer: las tecnologías digitales se dirigen al usuario como un sujeto maleable a quien hay que sugerirle constantemente lo que quiere.

A la vez, plantea ciertas dudas con respecto a la digitalización de toda la información - desde los textos, hasta los videos y la música- y su accesibilidad sin inconvenientes o restricciones, debido a que este proceso se realiza en el ámbito de un mercado globalizado de un modo de producción capitalista. Este contexto diluye la fantasía de un sistema de comunicación transparente y horizontal en el cual se producen intercambios sin conflictos, propia de un discurso predominante en la actualidad. En este sentido, plantea que resulta una ilusión pensar en la aparición de un intercambio virtual y digital "sin fricción" en las condiciones sociales contemporáneas, ya que justamente lo que oculta ese discurso es el conjunto de relaciones de poder - de decisiones políticas, de condiciones institucionales- donde emerge Internet (Žižek, 2007).

\section{La participación como transmisión}

Otro investigador crítico de las afirmaciones que pregonan una participación colaborativa de los internautas, es Greg Goldberg (2011). Este sociólogo estadounidense plantea que en realidad lo que está aconteciendo en Internet no es justamente la producción, sino más bien una transmisión de contenidos digitales. Esa es una de sus hipótesis centrales: las empresas se encuentran en una situación en la cual los internautas difunden sus bienes simbólicos de manera gratuita a través de la red.

Según Goldberg, lo que a menudo es teorizado como una eliminación o liberación de las restricciones económicas que limitaban la propagación de contenidos culturales, es en realidad un cambio de las relaciones de intercambio por otras de transmisión. O sea que en la red la participación es un acto de comercio. Las instancias de participación 
implican una transferencia de datos que se han economizado, impulsan la rentabilidad y viabilidad de la industria de redes y de las empresas basadas en Internet, como Google o Facebook: la participación de los internautas es la base económica de las industrias de redes. ${ }^{2}$

Los usuarios, entonces, beneficiarían a las industrias del entretenimiento y los medios masivos de difusión justamente al retransmitir sus contenidos. Por ejemplo, reproducir íntegramente una noticia publicada en un diario en línea para que otros internautas la lean, constituye una promoción de ese medio, que se verá beneficiado por el ingreso a su portal de noticias. Por tal

2 Este argumento también es sostenido por los británicos Chris Land y Steffen Böhm, al afirmar que los usuarios de Facebook pueden ser considerados como trabajadores sin remuneración. La práctica de actualizar el Estado, realizar comentarios a los amigos o compartir videos y fotos, puede ser entendida como una "actividad de producción de valor". Toda esta información justamente es utilizada por Facebook como materia prima básica para producir datos de mercadeo acerca de sus usuarios que se pueden aprovechar para fines de investigación de mercado y de publicidad. Ver el artículo "They are exploiting us! Why we all work for Facebook for free", de Chris Tierra y Böhm Steffen, publicado el 22 de febrero de 2012 en el sitio web Organizations, Occupations and Work, recuperado en http://oowsection. org/2012/02/22/they-are-exploiting-uswhy-we-all-work-for-facebook-for-free/. motivo, Goldberg afirma que los estudiosos de la comunicación deberían tener una mirada crítica sobre los esfuerzos permanentes por parte de las empresas del sector para aumentar la participación de los usuarios.

Así entonces, en lugar de entender a la red como el ámbito donde existe la posibilidad de un intercambio comunicativo libre de los intereses del capital, habría que sostener la hipótesis de que este sistema de producción basado en la transmisión tiene íntimas relaciones con el capital transnacional concentrado. Los internautas hacen transmisión de contenidos culturales en sus diarios cibernéticos o en las redes sociales y de esa forma fortalecerían a las grandes empresas.

Al contrario de Jenkins, este autor asegura que la reorganización de las economías de la cultura en torno a las relaciones de la transmisión complica la política de participación en todas sus formas, en la medida en que la participación no es simplemente una forma de ejercer o resistir el poder, sino de canalizar o entregar el poder de la información (Goldberg, 2011).

Esta afirmación constituye una cierta ruptura con un discurso de 
época que tiene a la conexión-participación-producción como ejes articuladores, discurso que supone un internauta activo que, por medio de plataformas virtuales, interviene en la vida social y política actual: un consumidor que, no solo mira la pantalla, sino que también interactúa con ella en una relación de diálogo.

Greg Goldberg entonces estaría discutiendo el pregonado carácter productivo de la conectividad. De esta forma, estar en la red no constituye en sí ser un usuario que produce contenidos. Puede decirse que la mayoría de los internautas utiliza la red para informarse y acceder a diversos bienes culturales, pero no para producir efectivamente contenido novedoso. Es decir, las potencialidades de las tecnologías digitales que posibilitan a sus usuarios crear y compartir contenidos se manifestarían en una transmisión de los materiales producidos y puestos en circulación con anterioridad.

Por lo tanto, desde esta perspectiva puede pensarse que la pregonada participación en línea no constituiría una producción colaborativa de nuevos contenidos, sino más bien una reproducción acrecentada. En consecuencia, la mayoría de las prácticas de los internautas se caracterizarían por una transmisión (o una recirculación en ámbitos virtuales) de contenidos de los medios de difusión o las industrias del entretenimiento.

\section{Conclusión}

El crecimiento constante del uso de artefactos que navegan en Internet ha modificado la forma de comunicarse de las personas y las posibilidades de acceso y difusión de información y datos, así como creado nuevas formas de control y nuevos poderes y mercados monopólicos. Este proceso se manifiesta en diversos ámbitos de la existencia: las comunicaciones, los transportes, las relaciones de poder, los mercados, la legislación, la producción artística y las estrategias informativas.

La digitalización de contenidos constituye una transformación en la creación artística y en los modelos de negocio de las industrias del entretenimiento. Pero, también, presenta un rasgo novedoso: le otorga - potencialmente- a cada usuario la posibilidad de crear y difundir sus producciones y materiales personales, o modificar los existentes con el fin de otorgarles otro sentido. Los internautas recrean y reconfiguran los contenidos digitales. Toda esta hibridación, re-composición, 
yuxtaposición, y el cortar y pegar de imágenes, sonidos y textos, ha transformado a Internet en una gran interfaz cultural en la que se efectúan las prácticas de ocio y entretenimiento de las sociedades contemporáneas.

La discusión ronda en torno al carácter productivo o reproductivo de las acciones de los internautas y si realmente es posible considerar sus prácticas como relevantes en el escenario cultural y comunicacional actual, y capaces de disputarle espacios a las empresas de entretenimiento tradicionales. Mientras que algunos autores ven en el uso de las tecnologías digitales la posibilidad de construir una cultura colaborativa y altruista basada en las acciones de los usuarios de la red, otros consideran que las actividades del ciberespacio constituyen una transferencia de datos que impulsan la rentabilidad de las empresas del sector y del capital financiero concentrado (sin olvidar tampoco el control que realizan los Estados nacionales).

\section{Referencias}

Bunz, M. (2007). La utopía de la copia. El pop como irritación. Buenos Aires: Interzona.
Castells, M. (2004). La sociedad red: una visión global. Madrid: Alianza Editorial.

García, N. (2007). Lectores, espectadores e internautas. Barcelona: Gedisa.

Goldberg, G. (2011). Rethinking the public/virtual sphere: The problem with participation. New $\mathrm{Me}$ dia \& Society. Recuperado el 6 de diciembre de 2010, en http://nms. sagepub.com/content/13/5/739.

Jenkins, H. et al. (2006). Confronting the Challenges of Participatory Culture: Media Education for the 21st Century. Chicago: The MacArthur Foundation.

Lévy, P. (2004). Inteligencia colectiva: por una antropología del ciberespacio. Washington: Organización Panamericana de la Salud.

Piscitelli, A. (2009). Nativos digitales. Dieta cognitiva, inteligencia colectiva y arquitecturas de participación. Buenos Aires: Santillana.

Rifkin, J. (2000). La era de acceso. Buenos Aires: Paidós.

Rüdiger, F. (2011). As teorías da Cibercultura. Porto Alegre: Sulina. 
Toffler, A. (1980). La tercera ola. - (2007). Pensar la comunicación. Bogotá: Plaza \& Janés.

Punto de vista para periodistas y po-

Urresti, M. (2008). Ciberculturas julíticos. Buenos Aires: Prometeo.

veniles. Buenos Aires: La Crujía.

Žižek, S. (2007). El acoso de las fan-

Wolton, D. (2000). Internet ¿y destasías. México: Siglo XXI.

pués? Barcelona: Gedisa. 